\title{
Effects of Intake of Milk Enriched with Aloe vera on Patients with Gastrointestinal Reflux Disease
}

\author{
Marta Sangil-Monroy¹, Lluís Serra-Majem1,2,3*, José M. Marrero Monroy4, \\ Adriana Ortiz Andrellucchi ${ }^{1,2}$, Almudena Sánchez-Villegas ${ }^{1,2}$, Jorge Doreste ${ }^{1}$, \\ Paul Knipschild 1 \\ ${ }^{1}$ Nutrition Research Group, Research Institute of Biomedical and Health Sciences, University of Las Palmas de \\ Gran Canaria, Las Palmas de Gran Canaria, Spain \\ ${ }^{2}$ Ciber de Fisiopatología de la Obesidad y Nutrición (CIBER OBN), Instituto de Salud Carlos III, Madrid, Spain \\ ${ }^{3}$ Service of Preventive Medicine, Hospital Universitario Insular de Gran Canaria, Servicio Canario de Salud, \\ Las Palmas de Gran Canaria, Spain \\ ${ }^{4}$ Department of Gastroenterology, Hospital Universitario Insular de Gran Canaria, Servicio Canario de Salud, \\ Las Palmas de Gran Canaria, Spain \\ Email: ${ }^{*}$ luis.serra@ulpgc.es
}

Received 25 February 2014; revised 25 March 2014; accepted 1 April 2014

Copyright (C 2014 by authors and Scientific Research Publishing Inc.

This work is licensed under the Creative Commons Attribution International License (CC BY).

http://creativecommons.org/licenses/by/4.0/

(c) (i) Open Access

\begin{abstract}
Background: Aloe vera has been used by many civilizations throughout history due to the numerous properties attributed. Gastro oesophageal reflux disease is a common disorder with consequences for the patient's health related quality of life. Aims: The purpose of this study was to assess the benefits of the Aloe vera in 80 patients with gastro oesophageal reflux. Methods: This is probably the first randomised and double-blind trail ever performed on this subject. The study included eight weeks of treatment with milk enriched with Aloe vera or placebo. Data of diet (frequency questionnaire), symptoms (gastrointestinal symptom rating scale) and quality of life (quality of life in reflux and disease) were obtained. Results: So far, there has been hardly any proof that Aloe vera decreases symptoms of reflux disease; on the contrary, a lower percentage of remission of pain is observed among the Aloe vera group. As long as its effectiveness has not been proven properly, the use of Aloe vera in reflux disease cannot be recommend. Conclusion: Aloe vera does not have a beneficial effect on reflux disease under the study conditions.
\end{abstract}

\section{Keywords}

Aloe vera, Alternative Treatment, Gastrointestinal Reflux (See MESH), Clinical Trial

\footnotetext{
${ }^{*}$ Corresponding author.
} 


\section{Introduction}

Aloe vera is used as a medication since already thousands of years. The gel of the plant, especially in the leaves, contains a large number of potentially active components, e.g., vitamins, minerals and certain saponins. For details see Vögler and Ernst [1]. They may have various effects and be helpful against a mix of diseases such as burns, dermatitis, diabetes and also certain diseases of the gastro-intestinal tract such as irritable bowel disease, ulcerative colitis and peptic ulcers [2] [3]. Recently, the production of Aloe vera has increased considerably now that it is advertised to be used in cosmetics and functional foods. It is said that, among other things, it is beneficial to patients with reflux disease, but the scientific evidence so far is very low [4] [5]. We do not know of any existing blinded placebo controlled randomised clinical trial in patients with the disease.

Gastro-oesophageal reflux disease (GERD) has been defined as chronic symptoms or mucosal damage produced by the abnormal reflux of gastric contents into the oesophagus [6]. The cardinal manifestation of GERD, heartburn, is experienced monthly by approximately $25 \%$ of adults in developed countries, if it occurs once a week and has been estimated to be $15 \%$ - 20\% [7], and while at least $5 \%$ have it daily. Such patients experience a decreased quality of life [8]. Numerous treatment studies of patients with GERD have shown that suppression of gastric acid can improve heartburn by healing oesophagitis or by reduction of oesophageal sensitivity to acid [6] [9].

Some patients with digest problems including reflux report that they feel better when they intake Aloe vera. The Aloe vera intake and different belief about his properties are quite common in the Canary Islands. The reason may be that it is a plant native of these islands where it has been used extensively over centuries. Here, its putative effect to diminish the symptoms of reflux disease in humans is studied.

\section{Material and Methods}

Adult's patients were taken from the Unit of Digestive Physiology of the University Hospital Materno Insular of Gran Canaria and from 3 Health Centres of Gran Canaria.

Cases were selected from hospital patients diagnosed with reflux disease without esofagitis. Further inclusion criteria were: no severe pathology, normal endoscope of the oesophagus and no abnormal pH-metre. To increase the number of cases, patients from 3 Health Centres of Gran Canaria were included as a second arm of our study, apart from the patients from the Hospital, using as a single criterion for inclusion in their case that they must suffer from symptoms of reflux disease.

All sorts of patients: with ulcer, earlier surgery in this area, other serious digestive diseases were excluded. Other exclusion reasons were psychiatric disease, alcohol or drugs use, asthma, allergies to the active substances included in the protocol, malabsorption, lactose intolerance, many systemic diseases such a heart, neuropathies, coagulopathies, metabolic and immune system diseases, endocrinopathies such as diabetes or thyroid dysfunction, liver or kidney diseases, and women who were pregnant or in lactation. For patients from Health Centres, the same exclusion criteria that we used in the Hospital were used.

Patients in the treatment arm of the experiment had to drink every day half a litre of milk with Aloe vera for a period of 8 weeks (Table 1). This milk was enriched with 15\% Aloe verabarbadensis Miller gel. It is the amount that is generally recommended by manufacturers of milk without changing the organoleptic, physical-chemical and microbiological characteristic of milk. The control group received the same milk in the same amount and package, but without the Aloe vera. The precise content of the treatments is given in a separate frame. The Spanish Drug Agency does not describe any interaction of almagate and milk, and no interaction described in the literature between Aloe vera and milk was found [10].

Patients were allowed to use concomitantly almagate (a crystalline hydrated aluminum-magnesium hydroxycarbonate), one dose three times a day, preferably half an hour after main meals if they considered it necessary, but they had to write down their use of the brand day by day.

A random allocation list with a block number of 6 to help increase equal numbers for the treatment and control arm was made. A person other than the primary investigators to improve a blinding procedure did the random allocation. Study did not start with a qualification period before randomization.

At the start before entering the experiment patients had to sign an informed consent form, give their sociodemographic data and medical history, and fill out two questionnaires related to reflux disease. They also had to write on a diary their compliance with the use of the study medication and almagate.

To evaluate the change of symptoms of reflux disease 2 questionnaires were used. The first one was the well- 
Table 1. Characteristics of the two groups studied.

\begin{tabular}{|c|c|c|c|c|c|}
\hline & \multicolumn{2}{|c|}{ Treat Group (n 40) } & \multicolumn{2}{|c|}{ Placebo Group (n 40) } & \multirow[t]{2}{*}{$p$} \\
\hline & Mean & SD & Mean & SD & \\
\hline Age (years) & 48.46 & 10.46 & 46.21 & 10.28 & 0.340 \\
\hline $\mathrm{BMI}\left(\mathrm{kgr} / \mathrm{m}^{2}\right)$ & 28.61 & 3.89 & 27.28 & 4.08 & 0.161 \\
\hline \multicolumn{6}{|l|}{ Gender (\%) } \\
\hline Male & \multicolumn{2}{|c|}{$45 \%$} & \multicolumn{2}{|c|}{$40 \%$} & \\
\hline Female & \multicolumn{2}{|c|}{$55 \%$} & \multicolumn{2}{|c|}{$60 \%$} & \\
\hline Severity of Reflux Symptoms & 3.37 & 1.09 & 2.89 & 0.96 & 0.047 \\
\hline Hospital (n 57) & 3.31 & 1.18 & 2.91 & 0.82 & 0.151 \\
\hline Health Centers (n 23) & 3.49 & 0.89 & 2.85 & 1.30 & 0.180 \\
\hline Severity of Reflux & 4.13 & 1.48 & 3.88 & 1.38 & 0.440 \\
\hline Hospital (n 57) & 4.28 & 1.69 & 4.05 & 1.29 & 0.559 \\
\hline Health Centers (n 23) & 3.79 & 0.78 & 3.45 & 1.60 & 0.523 \\
\hline Severity of Pain & 3.55 & 1.34 & 3.09 & 1.20 & 0.113 \\
\hline Hospital (n 57) & 3.66 & 1.34 & 3.13 & 1.14 & 0.116 \\
\hline Health Centers (n 23) & 3.27 & 1.36 & 2.96 & 1.41 & 0.601 \\
\hline Quality of Life & 4.39 & 1.23 & 4.65 & 1.34 & 0.373 \\
\hline Hospital & 4.27 & 1.28 & 4.48 & 1.19 & 0.543 \\
\hline Health Centers & 4.62 & 1.12 & 5.10 & 1.67 & 0.426 \\
\hline
\end{tabular}

known Gastrointestinal Symptom Rating Scale (GSRS) [11]-[13]. It contains 15 items, divided into reflux (2), indigestion (4), constipation (3), abdominal pain (3) and diarrhoea (3). A Likert scale with 7 grades and an increase scale for every item was used. The GSRS is a validated scale that is used often in reflux disease studies. Earlier it was adapted for use in Spanish countries [14] [15]. Our main interest for this study was in setting changes of the overall score, and separately for reflux and pain, comparing this change between the treatment and control group of patients.

To measure the influence of reflux disease on health related quality of life the Quality Of Life in Reflux and Disease (QOLRAD) was also used. This questionnaire contains 25 items, divided into emotions (6), vitality (3), sleeping (5), diet (6) and physical-social functioning (5) [16] [17]. Also this questionnaire has a Likert scale of 7 grades, but in contrast to the GSRS lower values indicate more impact on daily functioning. In the analysis the order of the QOLRAD was changed to keep up with the GSRS in establishing the effect of Aloe vera. The QOLRAD was also validated earlier [15] and adapted for use in Spanish countries.

Dropouts are discussed in the results section. In case of missing values we used the mean of the other values if $50 \%$ of more were completed. The change of symptoms was individually established with the formula \% remission $=(\mathrm{Pf}-\mathrm{Pi}) / \mathrm{Pi} \times 100$, in which $\mathrm{Pi}$ is the score at the start and Pf after 8 weeks. Beforehand and due to the absence of previous studies, the median of the change of symptoms in the control group to be $30 \%$ and the change in the treatment group to be $50 \%$ or more were considered. With $\alpha=0.05$ two-sided and $\beta=0.20$ this give 42 patients in both groups.

Differences on the median change in the two groups are tested with a median test and presented with their $10 \%-90 \%$ intervals.

The study was approved by the Medical Ethical Committee of the hospital (University Hospital Materno Insular de Gran Canaria). It was not registered beforehand to the official trial office.

\section{Results}

The inclusion of the patients and their follow up was started and finished in 2006. Originally, there were 80 patients in our study 57 from the hospital, augmented with 23 from the Health Centres.

Unfortunately, a quite a number of dropouts was observed, although not always because patients were in the 
study. Six patients left the study for reasons unrelated to treatment, other six by insufficient treatment and three more for unknown reason.

Be this as it may, it leaves with in total 65 reflux patients with data at the start and after 8 weeks, 33 in the treatment and 32 in the control group. The number of patients from the hospital was 47 and from the Health Centre 18.

Researchers were unaware of who was in which group, treatment or control. The analysis was not done individually and then per group, but straight dividing the patients in-group A and B. Somebody else than the main researcher did the random allocation.

Compliance of the treatment and of almagate was controlled with the diary. 18 treatment patients out of 21 and 16 out of 19 control patients had consumed almagate. The median (daily) in the treatment group was 0.5 and 1 in the control group.

The most relevant results are described in Table 2. As for the overall GSRS score, the treatment group started with a median score of 3.1 and it decreased to 2.9 after 8 weeks. In the control group these were 2.7 and 2.3. For 30 patients in the treatment group and 31 patients in the control group complete data on everything was obstained. The number of patients with lesser symptoms in general was 17 out of 30 in the treatment group and 22 out of 31 in the control group. Therefore, any effect of Aloe vera on symptoms of reflux disease was found.

Separately for reflux only a change in the expected direction of 0.75 points in the treatment group was found, but also 0.75 in the control group. In 19 out of 33 treatment patients the symptoms had improved, in 19 out of 32 control patients the symptoms improved.

As for a change in pain, related to Aloe vera, it was 0.16 and 0.66 , respectively, and the remission was $5.5 \%$ and $21 \%$ respectively $(t=-2.315 ; p=0.025)$. The number of patients with improving of symptoms was 15 out of 30 in the treatment group and 22 out of 32 in the control group. If anything, this result is in the opposite direction, certainly not in the expected direction.

The quality of life data was also studied. The median for the treatment group changed from 4.2 to 4.8 and in the control group from 4.4 to 5.7 (change QOLRAD Scale, setting the other way round, to make that "improvement" means a reduction, not an augmentation of the index). The difference was 0.2 and 0.42 respectively. Again, we could not find any indication at all that Aloe vera had a beneficial effect.

Looking at the data for the hospital patients separately do not change the results.

Table 2. Changes in questionnaires GSRS (overall symptomatology, only reflux, only pain) and QOLRAD (quality of life) comparing the beginning and end of treatment.

\begin{tabular}{|c|c|c|c|c|c|}
\hline & \multicolumn{2}{|c|}{ Treat Group } & \multicolumn{2}{|c|}{ Placebo Group } & \multirow{2}{*}{$p$} \\
\hline & Initial & Final & Initial & Final & \\
\hline \multicolumn{6}{|l|}{ GSRS } \\
\hline Mean (range) & $3.1(1.5-5.7)$ & $2.9(1.1-6.1)$ & $2.7(1.5-6.0)$ & $2.3(1.1-5.0)$ & \\
\hline Difference & \multicolumn{2}{|c|}{0.30} & \multicolumn{2}{|c|}{0.40} & 0.531 \\
\hline \% remission & \multicolumn{2}{|c|}{$11.23 \%$} & \multicolumn{2}{|c|}{$19.04 \%$} & 0.565 \\
\hline \multicolumn{6}{|l|}{ GSRS (reflux) } \\
\hline Mean (range) & $4(1.5-7.0)$ & $3.5(1.0-7.0)$ & $4(1.0-7.0)$ & $2.5(1.0-6.5)$ & \\
\hline Difference & \multicolumn{2}{|c|}{0.75} & \multicolumn{2}{|c|}{0.75} & 0.632 \\
\hline \% remission & \multicolumn{2}{|c|}{$17.36 \%$} & \multicolumn{2}{|c|}{$15.47 \%$} & 0.684 \\
\hline \multicolumn{6}{|l|}{ GSRS (pain) } \\
\hline Mean (range) & $3.3(1.3-6.0)$ & $3.0(1.0-6.0)$ & $2.8(1.0$ - 5.6) & $2.0(1.0-4.6)$ & \\
\hline Difference & \multicolumn{2}{|c|}{0.16} & \multicolumn{2}{|c|}{0.66} & 0.083 \\
\hline \% remission & \multicolumn{2}{|c|}{$5.5 \%$} & \multicolumn{2}{|c|}{$20.9 \%$} & 0.025 \\
\hline \multicolumn{6}{|l|}{ QOLRAD } \\
\hline Mean (range) & $4.2(2.4-6.5)$ & $4.8(2.0-7.0)$ & $4.4(1.5-7.0)$ & $5.7(1.8-7.0)$ & \\
\hline Difference & \multicolumn{2}{|c|}{-0.20} & \multicolumn{2}{|c|}{-0.42} & 0.462 \\
\hline \% remission & \multicolumn{2}{|c|}{$-5.6 \%$} & \multicolumn{2}{|c|}{$-11.9 \%$} & 0.326 \\
\hline
\end{tabular}




\section{Discussion}

So it looks that this study does not find any beneficial effect of Aloe vera. It does not seem to exist a problem of dosage but there may be a problem of duration in our study. Other authors advocate a higher amount of Aloe vera daily to be used for a longer period. The effects of plants food supplements are subtle, as for any dietary intervention [18]. Chronic intervention could be necessary if we look for diminishing the symptoms of diseases such as reflux disease. One does not know for sure, what is the putative best dosage/duration, but after this study it is up to others to prove any different amounts.

Most of patients from this study have a clear reflux disease in a severity form, and, well and all; a 17\% of remission in the treat group and a 15\% in the control group were found. Due to the subtle effects of the plant food supplements, better result may have been obtained if the patients included were in the first steps of the reflux disease. Maybe the aloe does not have strong effects for patients with longer lasting reflux, especially if the discomfort of the symptoms was considered, but it could have some effect usefully for minor reflux. In the other hand, the study population shows a great concern to abandon the usual treatment; this concern could negatively influence the treatment and improvement of patient, but may add other possible concerns about their quality of life.

More importantly, and as a caveat to these results, in retrospect we are not fully satisfied with the severity and number of patients recruited. Some of the patients, especially those coming from the Health Centre, may have had a reflux disease in a minor form.

Moreover, some limitations could be considered. It was quite an enterprise to get enough patients for this controlled experiment. Therefore, it is possible that a small effect if any was missed. Apart from that, the number of dropouts could have been reduced by restricting the study to patients with a clear disease but with fewer complications and maybe a less severe or frequency gastro-oesophageal reflux. The frequency of reflux may be important by increasing the total amount of highly concentrated damaging substances, either by prolonging distal mucosal exposure [19]. Also for that reason, we advise investigators of later studies into this subject to start with a larger sample of patients.

The use of almagate was allowed to the patients, if they thought it necessary. The control group use double of almagate than the treat group. Maybe it has missed a hidden effect of the Aloe vera.

Afterwards, we wonder whether a harmful effect of Aloe vera on reflux disease was found. Especially its effect on pain was contrary to what expected beforehand. For the moment our position is that we consider this effect on pain a chance result, but if it is confirmed in later studies, there may be reason to advice against the use of Aloe vera for reflux disease pain. It should be taken into account that Aloe vera is one of the most popular consumed plant food supplements across Europe [20].

\section{Conclusion}

Finally, what do we think about all the existing evidences? So far, there has been hardly any proof that Aloe vera decreases symptoms of reflux disease. The idea comes to some extent from the laboratory and mainly from descriptions of individual patients. For some proponents of Aloe vera, this may be enough to promote it as a nutritional drug, but we are of a different opinion [18]. As long as its effectiveness has not been proven properly, its use in reflux disease cannot be recommend. This study is the first published randomised, blinded study on this subject. And it is not positive for Aloe vera, if anything; a deleterious effect is even found. We conclude that Aloe vera probably does not have a beneficial effect on reflux disease, although it may be a little premature.

\section{Acknowledgements}

The study was supported by a Contract between Central Lechera Asturiana (CAPSA) and Fundación Universitaria de Las Palmas (Contract $n^{\circ}$ 141/05 240/05/58). The Dairy Company CAPSA aimed to introduce an Aloe vera enriched milk in the Spanish market with a specific claim/use for digestive symptoms, but due to the observed results, the project was abandoned. This study could be shown as a good practice of unexisting conflicts of interest between financing from the private sector and research and publication policies of negative results.

\section{References}

[1] Vögler, B.K. and Ernst, E. (1999) Aloe vera: A Systematic Review of Its Clinical Effectiveness. The British Journal of 
General Practice, 49, 823-828.

[2] Grindlay, D. and Reynolds, T. (1986) The Aloe vera Phenomenon: A Review of the Properties and Modern Uses of Leaf Parenchyma Gel. Journal of Ethnopharmacology, 16, 117-151. http://dx.doi.org/10.1016/0378-8741(86)90085-1

[3] Langmead, L., Feakins, R.M., Goldthorpe, S., et al. (2004) Randomized, Double-Blind, Placebo-Controlled Trial of Oral Aloe vera gel for Ulcerative Colitis. Alimentary Pharmacology \& Therapeutics, 19, 739-747. http://dx.doi.org/10.1111/j.1365-2036.2004.01902.x

[4] Blitz, J., Smith, J.W. and Gerard, J.R. (1963) Aloe vera Gel in Peptic Ulcer Therapy: Preliminary Report. Journal of the American Osteopathic Association, 62, 731-735.

[5] Eshun, K. and He, Q. (2004) Aloe vera: A Valuable Ingredient for the Food, Pharmaceutical and Cosmetic Industries-A Review. Critical Reviews in Food Science and Nutrition, 44, 91-96. http://dx.doi.org/10.1080/10408690490424694

[6] Kahrilas, P.J. (2008) Gastroesophageal Reflux Disease. The New England Journal of Medicine, 359, 1700-1707. http://dx.doi.org/10.1056/NEJMcp0804684

[7] Lagergren, J. and Bergström, N.O. (2000) No Relation between Body Mass and Gastro-Oesophageal Reflux Symptoms in a Swedish Population Based Study. Gut, 47, 26-29. http://dx.doi.org/10.1136/gut.47.1.26

[8] Van Pinxteren, B., Numans, M.E., Lau, J., et al. (2003) Short-Term Treatment of Gastroesophageal Reflux Disease. Journal of General Internal Medicine, 18, 755-763. http://dx.doi.org/10.1046/j.1525-1497.2003.20833.x

[9] El-Serag, H.B., Sonnenberg, A., Jamal, M.M., et al. (1999) Corpus Gastritis Is Protective against Reflux Oesophagitis. Gut, 45, 181-185. http://dx.doi.org/10.1136/gut.45.2.181

[10] (2012) Ficha Técnica o Resumen de las Características del Producto: Almax (Internet). España: Agencia Española del Medicamento y Productos Sanitarios.

http://www.aemps.gob.es/cima/especialidad.do?metodo=verFichaWordPdf\&codigo=66531\&formato=pdf\&formulario =FICHAS

[11] Revicki, D.A., Word, M., Winklun, I., et al. (1998) Reliability and Validity of Gastrointestinal Symptom Rating Scale en Patients with Gastroesophageal Reflux Disease. Quality of Life Research, 7, 75-83. http://dx.doi.org/10.1023/A:1008841022998

[12] Revicki, D.A., Sorensen, S., Maton, P.N., et al. (1998) Health-Related Quality of Life Outcomes of Omeprazole versus Ranitidine in Poorly Responsive Symptomatic Gastroesophageal Reflux Disease. Digestive Diseases, 16, $284-291$. http://dx.doi.org/10.1159/000016878

[13] Havelund, T., Lind, T., Wiklund, I., et al. (1999) Quality of Life in Patients with Heartburn but without Esophagitis: Effects of Treatment with Omeprazole. The American Journal of Gastroenterology, 94, 1782-1789. http://dx.doi.org/10.1111/j.1572-0241.1999.01206.x

[14] Moreno Elola-Olaso, C., Rey, E., Rodríguez-Artalejo, F., et al. (2002) Adaptación y Validación de un Cuestionario Sobre Reflujo Gastroesofágico para Uso en Población Española. Revista Española de Enfermedades Digestivas, 94, 745-751.

[15] Kulich, K.R., Piqué, J.M., Vegazo, O., et al. (2005) Psychometric Validation of the Spanish Translation of Gastrointestinal Symptom Rating Scale (GSRS) and Quality of Life in Reflux and Dyspepsia (QOLRAD) Questionnaire in Patients with Reflux Disease. Española Clínica Española, 205, 588-594. http://dx.doi.org/10.1016/S0014-2565(05)72651-5

[16] Talley, N.J., Fullerton, S., Junghard, O., et al. (2001) Quality of Life in Patients with Endoscopy-Negative Heartburn: Reliability and Sensitivity of Disease-Specific Instruments. The American Journal of Gastroenterology, 96, 1998-2004. http://dx.doi.org/10.1111/j.1572-0241.2001.03932.x

[17] Kulig, M., Leodolter, A., Vieth, M., et al. (2003) Quality of Life in Relation to Symptoms in Patients with Gastroesophageal Reflux Disease: An Analyses Based on the Pro-GERD Initiative. Alimentary Pharmacology \& Therapeutics, 18, 767-776. http://dx.doi.org/10.1046/j.1365-2036.2003.01770.x

[18] Williamson, G., Coppens, P., Serra-Majem, L., et al. (2011) Review of the Efficacy of Green Tea, Isoflavones and Aloe vera Supplements Based on Randomised Controlled Trials. Food \& Function, 2, 753-759. http://dx.doi.org/10.1039/c1fo10101c

[19] Sifrim, D. (2005) Relevance of Volume and Proximal Extent of Reflux in Gastro-Oesophageal Reflux Disease. Gut, 54, 175-178. http://dx.doi.org/10.1136/gut.2004.043984

[20] Garcia-Alvarez, A., Egan, B., de Klein, S., et al. (2014) Usage of Plant Food Supplements across Six European Countries: Findings from the PlantLIBRA Consumer Survey. PLoS One, 9, Article ID: e92265.

http://dx.doi.org/10.1371/journal.pone.0092265 
M. Sangil-Monroy et al.

\section{Abbreviation}

GERD: Gastro-Oesophageal Reflux Disease.

GSRS: Gastrointestinal Symptom Rating Scale.

QOLRAD: Quality of Life in Reflux and Disease.

CAPSA: Central Lechera Asturiana. 